\title{
Monitoramento de desastres em rios empregando sensoriamento remoto: análise comparativa da turbidez e da reflectância no Rio Doce
}

O rompimento da barragem de Fundão em Mariana/MG, foi um dos desastres ambientais mais impactante da história do Brasil até então. Milhões de rejeitos de mineração foram lançados no Rio Doce, ocasionando a mortandade da biodiversidade aquática e da fauna terrestre, além de causar a perda de várias pessoas, a destruição do município de Bento Rodrigues e de desabrigar muitas famílias. Tal evento não é um caso isolado e a detecção e monitoramento do deslocamento destes rejeitos é extremamente importante visto que em muitos casos são necessárias ações preventivas para resguardar a integridade de populações e atividades econômicas que depende da água captada nos rios, contudo este é oneroso em função do deslocamento de equipes que coletam amostras (ou realizam análise In Locu) para a deteç̧ão da presença dos rejeitos. Assim, este trabalho se propõe ao desenvolvimento de uma metodologia para o monitoramento de desastres advindos do rompimento de barragens de rejeitos de mineração ao longo dos cursos d'água, por meio de sensoriamento remoto. Foram empregados os dados de Turbidez dos pontos de monitoramento existentes ao longo do Rio Doce, do Instituto Mineiro de Gestão das Águas (IGAM), e do Instituto Estatual do Meio Ambiente do Espirito Santo (IEMA), e cenas do satélite LandSat 8, Sensor OLI. Foi realizada a correção atmosférica das imagens selecionadas. Dos trinta e um pontos avaliados, todos que apresentaram maiores teores de turbidez apresentaram valores de refletância inferiores a 1 , o que levou a concluir que quanto maior o valor da turbidez, menor será a Reflectância da água analisada após a adição de rejeitos, da mineração de ferro, em grandes volumes contrariando o esperado.

Palavras-chave: Desastres ambientais; Sensoriamento remoto; Resposta espectral.

\section{Disaster monitoring in rivers using remote sensing: comparative analysis of turbidity and reflectance in Rio Doce}

\begin{abstract}
The rupture of the Fundão dam in Mariana/MG, was one of the most shocking environmental disasters in the history of Brazil until then. Millions of mining tailings were dumped in the Doce River, causing the death of aquatic biodiversity and terrestrial fauna, as well as causing the loss of several people, the destruction of the municipality of Bento Rodrigues, and the destitution of many families. This event is not an isolated case and the detection and monitoring of the displacement of these wastes is extremely important since in many cases preventive actions are necessary to protect the integrity of populations and economic activities that depends on the water captured in the rivers, but this is costly in (or perform In Locu analysis) to detect the presence of tailings. Thus, this work proposes the development of a methodology for the monitoring of disasters arising from the disruption of mining tailings dams along the watercourses through remote sensing. The Turbidity data of the existing monitoring points along the Doce River, the Institute of Water Management (IGAM), and the Environmental Institute of Espirito Santo (IEMA) were used, as well as scenes from the LandSat 8, Sensor OLI. Atmospheric correction of selected images was performed. From the thirty-one points evaluated, all those with higher turbidity levels presented values of reflectance lower than 1 , which led to the conclusion that the higher the turbidity value, the lower the reflectance of the water analyzed after the addition of tailings, from mining of iron, in large volumes contrary to expectations.
\end{abstract}

Keywords: Environmental disasters; Remote sensing; Spectral response.

Topic: Tecnologia, Modelagem e Geoprocessamento

Reviewed anonymously in the process of blind peer.

Giovana Cabral Cazassa

Universidade Federal de Itajubá, Brasil

http://lattes.cnpq.br/4953875672188278

giovanacazassa@hotmail.com

\section{Marcella Cunha dos Santos}

Universidade Federal de Itajubá, Brasil

http://lattes.cnpq.br/6477887005230126

cscella18@gmail.com

Thaís Gonçalves de Oliveira

Universidade Federal de Itajubá, Brasil

thaisoliveira.unifei@gmail.com

d

DOI: 10.6008/CBPC2179-6858.2018.005.0027
Received: 10/06/2018

Approved: 24/07/2018

\begin{abstract}
Pedro Henrique Rodrigues Pereira (i)
Universidade Federal de Itajubá, Brasil

http://lattes.cnpq.br/1167097519077235

http://orcid.org/0000-0002-9837-403X

pedro.hrp90@gmail.com

José Augusto Costa Gonçalves (iD

Universidade Federal de Itajubá, Brasil

http://lattes.cnpq.br/1406590880915046

http://orcid.org/0000-0003-1659-0896

jaucosta@unifei.edu.b

Eliane Maria Vieira (iD

Universidade Federal de Itajubá, Brasil

http://lattes.cnpq.br/59973375541777088

http://orcid.org/0000-0003-1749-6105

elianemv@yahoo.com.br
\end{abstract}

\section{Referencing this:}

CAZASSA, G. C.; SANTOS, M. C.; OLIVRIRA, T. G.; PEREIRA, P. H. R.; GONÇALVES, J. A. C.; VIEIRA, E. M.. Monitoramento de desastres em rios empregando sensoriamento remoto: análise comparativa da turbidez e da reflectância no Rio Doce. Revista Ibero Americana de Ciências Ambientais, v.9, n.5, p.308-318, 2018. DOI:

http://doi.org/10.6008/CBPC2179-6858.2018.005.0027 


\section{INTRODUÇÃO}

Minas Gerais é o estado no qual a atividade mineradora mais se concentra no país. Segundo o Instituto Brasileiro de Mineração (IBRAM), o estado extrai em torno de 160 milhões de toneladas por ano de minério de ferro, é responsável por cerca de $53 \%$ da produção brasileira de minerais metálicos e $29 \%$ de minérios em geral. A atividade mineradora está presente em mais de 250 municípios mineiros, dentre eles tem-se a cidade de Mariana.

A mineração sempre foi uma das principais atividades econômicas deste estado, gerando renda, e também causando impactos ambientais e sociais, positivos e/ou negativos, como a geração de emprego e renda (impactos positivos), e a supressão da vegetação, o assoreamento de corpos hídricos, morte de animais, além de contaminação de fatores abióticos, como água e solo (impactos negativos) (LANA, 2015).

Segundo Bias et al. (2013), a carga de efluentes, orgânicos e inorgânicos, carreada para os recursos hídricos também afetam a luminosidade que penetra na coluna d'agua, modificando, consequentemente, o sistema de trocas gasosas. Os problemas gerados pela mineração estão diretamente relacionados ao tipo de minério explorado, como exemplo, para a exploração de minérios como o ferro, que são explorados em áreas montanhosas, e necessitam da construção de taludes, geram problemas como o alto carregamento de sedimentos pela drenagem, causando assoreamentos, e ainda, dificultando a regeneração natural das minas desativadas (LANA, 2015).

Além destes problemas que se instalam com a exploração dos minérios, ainda há os rompimentos das barragens de rejeitos, que embora possa ser considerado como um problema indireto, visto que a segurança da barragem é responsabilidade da mineradora, tais casos vêm ocorrendo ao longo dos anos no Brasil. Em Minas Gerais, eventos semelhantes tem ocorrido desde 1986, com relevantes perdas humanas, econômicas e ambientais, como o rompimento da barragem do Grupo Itaminas em Itabirito em 1986, da barragem da empresa Mineração Rio Verde em 2001 na cidade de Nova Lima, da Indústria Cataguases de Papel em Cataguases em 2003, da então Mineração Rio Pomba Cataguases em Miraí em 2007, da Companhia Siderúrgica Nacional em Congonhas em 2008, da Herculano Mineração novamente em Itabirito em 2014 e mais recentemente a da Samarco Mineração em Mariana em 2015, que afetou toda a extensão da bacia do Rio Doce (COSTA et al., 2016).

Quando os rejeitos atingem o curso d'água, tendem a ser carreados (quando em volume que se dilui nas águas dos rios) ou se deslocam seguindo o leito do rio (quando o volume é superior à capacidade de diluição das águas dos rios), podendo percorrer grandes distancias. O monitoramento do deslocamento destes rejeitos é de extrema importância, visto que em muitos casos são necessárias ações preventivas para resguardar a integridade de populações e atividades econômicas que depende da água captada nos rios. Este monitoramento é oneroso em função do deslocamento de equipes que coletam amostras (ou realizam análises In Lócus) para a detecção da presença dos rejeitos.

Neste contexto, este trabalho se propõe ao desenvolvimento de uma metodologia para o monitoramento de desastres advindos do rompimento de barragens de rejeitos de mineração ao longo dos 
cursos d'água, por meio de sensoriamento remoto, tendo como região de estudo o leito do rio Doce após o rompimento da barragem de Fundão pertencente ao complexo minerário de Germano, localizada no município de Mariana/MG.

\section{REVISÃO TEÓRICA}

\section{Sensoriamento Remoto como instrumento de análise de parâmetros de qualidade da água}

Segundo Bias (2013), dentre os métodos para a obtenção de informações associadas a parâmetros de qualidade da água, o sensoriamento remoto abriu uma nova perspectiva nos estudos hídricos por meio da análise da resposta eletromagnética deste recurso natural. Segundo Moreira (2012), o sensoriamento remoto está ligado à medida da radiação eletromagnética, refletida ou emitida dos alvos da superfície terrestre, bem como o tratamento e a disponibilização dessas informações de forma que sejam passíveis de interpretação. Ele tem sido um instrumento de grande valor para o monitoramento ambiental, pois com ele pode-se observar a resposta espectral dos elementos que irá demonstrar alterações na água, solo, umidade, vegetação, atmosfera, material orgânico, minerais, etc.

As frações refletidas e emitidas são importantes do ponto de vista de sensoriamento remoto, porque o fundamento dessa tecnologia se baseia na quantificação dessas radiações. A partir da análise da quantidade da radiação refletida e, ou, emitida pode-se inferir sobre o alvo imageado (MOREIRA, 2012). A água é encontrada sob diversas formas no ambiente e cada uma delas a absorção da radiação eletromagnética é diferente. A figura abaixo mostra as curvas de reflectância da água nos estados líquido, sólido e gasoso.

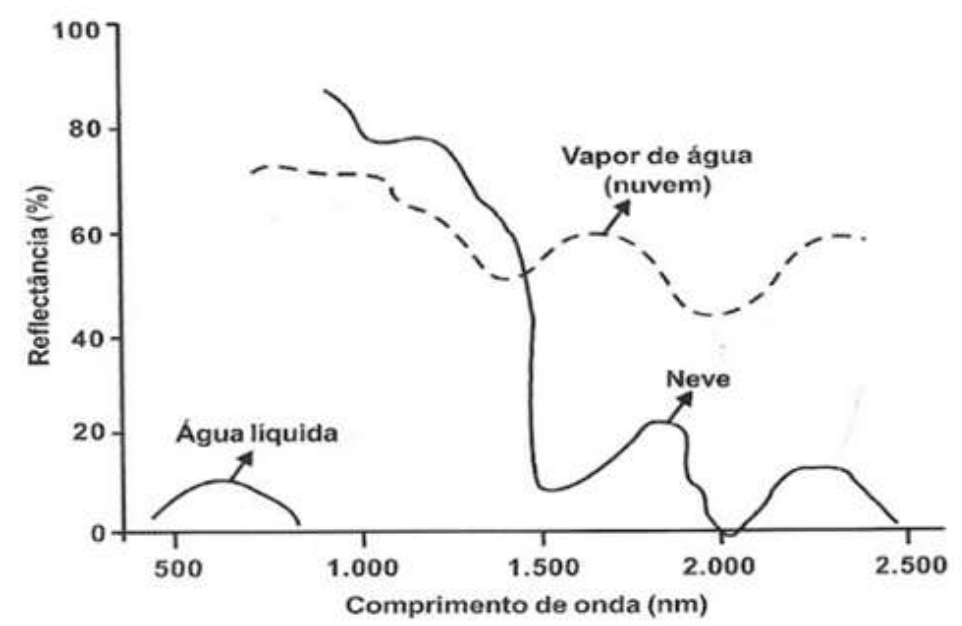

Figura 1: Curvas de reflectância da água nos estados sólido, líquido e gás. Fonte: Moreira (2012).

Ressalta-se, ao observar o gráfico acima, a água no estado líquido e pura absorve toda a radiação eletromagnética abaixo de $380 \mathrm{~nm}$ e acima de $700 \mathrm{~nm}$, ou seja ela é uma forte absorvedor da radiação em quase todas as faixas do espectro eletromagnético, tendo portanto como faixa de resposta espectral estes valores, entre 0,38 $\mu \mathrm{m}$ e 0,7 $\mu \mathrm{m}$, apresentando um baixo índice de refletância. Porém, alguns componentes opticamente ativos afetam a relação do padrão de resposta espectral da água. 


\section{Fatores que Interferem na Reflectância da Água}

Segundo Novo (2008) os fatores que podem interferir na reflectância da água são organismos vivos (fitoplancton, zooplancton e bacterioplancton); partículas em suspensão, orgânicas ou inorgânicas; e substancias orgânicas dissolvidas. O fitoplâncton também é responsável por parte da absorção e espalhamento da radiação solar e determinar as propriedades ópticas da água. A matéria orgânica que está presente nas águas é advinda dos fitoplânctons, seres aquáticos microscópicos que têm a capacidade de fazer fotossíntese, e estão presentes nelas compostos húmicos que definem a acidez do meio líquido e os ácidos fúlvicos. A presença desses compostos na água produz bandas de absorção altas no espectro ultravioleta, e a medida que esta concentração aumenta no meio aquático, a sua reflectância diminui (MOREIRA, 2012).

Segundo Ferreira et al. (2009), presenças de partículas orgânicas e inorgânicas na água aumentam o seu coeficiente de absorção, apresentando espectro de absorção semelhante ao da matéria orgânica, mas sua magnitude e bem menor. Já segundo Moreira (2012), as partículas de minerais inorgânicos, provenientes de solos e de rochas, é o parâmetro mais importante para o espalhamento da radiação na água, contudo depende de sua granulometria e constituição química.

\section{0 rio Doce}

O rio Doce é formado a partir do encontro de dois outros rios, o Rio Piranga e o Rio Ribeirão do Carmo; suas nascentes estão localizadas na Serra da Mantiqueira no município de Ressaquinha/MG e Serra do Espinhaço no município de Ouro Preto/MG, respectivamente. A bacia do rio Doce situa-se na região Sudeste, entre os paralelos $17^{\circ} 45^{\prime}$ e $21^{\circ} 15^{\prime} \mathrm{S}$ e os meridianos $39^{\circ} 30^{\prime}$ e $43^{\circ} 45^{\prime} \mathrm{W}$, integrando a região hidrográfica do Atlântico Sudeste. Esta bacia possui uma área de drenagem de aproximadamente 86.715 $\mathrm{km}^{2}$, dos quais $86 \%$ pertencem ao Estado de Minas Gerais e o restante ao Espírito Santo, abrangendo um total de 230 municípios (PIRH, 2010).

Em Minas Gerais, a bacia do Rio Doce é subdividida em seis Unidades de Planejamento e Gestão dos recursos hídricos, às quais correspondem as seguintes sub-bacias hidrográficas, a do rio Piranga (DO1), rio Piracicaba (DO2), rio Santo Antônio (DO3), rio Suaçuí Grande (DO4), rio Caratinga (DO5) e rio Manhuaçu (DO6) (Instituto Mineiro de Gestão das Águas). A turbidez, segundo o monitoramento realizado pelo IGAM ao longo do Rio Doce, não apresenta valores elevados, como pode ser constado no gráfico 01, onde o valor médio de turbidez para o período de 2012 a 2014 não ultrapassa o 75 NTU, com o maior valor monitorado no referido período para o ponto RD033 de 955 NTU.

Segundo o estudo realizado por Viola et al. (2015), do total de estações de amostragens do IGAM ao longo do Rio Doce, 14,6\% apresentara violação do limite estabelecido pela DN COPAM CERH 01/2005 (100 UNT), no período de 1997 a 2005. Segundo o mesmo autor, os valores encontrados são consequência do uso e ocupação do solo na bacia, com predominância da pecuária, e do despejo de esgoto urbano. 


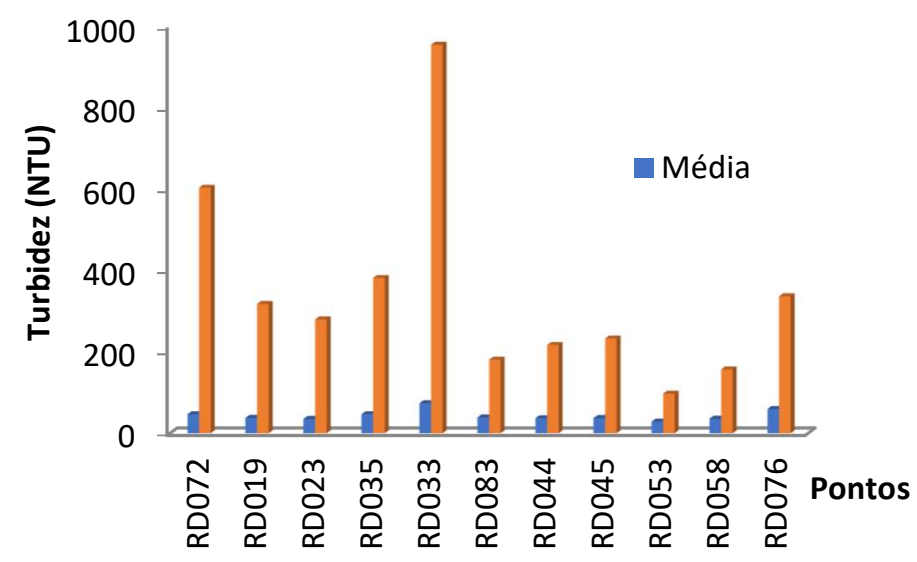

Gráfico 1: Valores de Turbidez média e máxima dos pontos monitorados pelo IGAM. Fonte: Adaptado de IGAM (2017).

\section{O desastre ambiental}

Em 5 de novembro de 2015, a barragem de Fundão pertencente ao complexo minerário de Germano, localizada no município de Mariana, se rompeu. Segundo ANA (2016), a barragem continha cerca de 50 milhões de metros cúbicos de rejeito de mineração de ferro, sendo que dessa quantidade 34 milhões de metros cúbicos foram lançados no meio ambiente, sendo o volume composto por rejeitos de mineração, água e materiais utilizados em sua construção. Segundo IBAMA (2015), o último laudo feito em 2014 na barragem, os rejeitos eram compostos por óxido de ferro e sílica (areia).

Inicialmente, esse rejeito atingiu a barragem de Santarém logo a jusante, causando seu galgamento e forçando a passagem de uma onda de lama por $55 \mathrm{~km}$ no rio Gualaxo do Norte até desaguar no rio do Carmo. Neste, os rejeitos percorreram outros $22 \mathrm{~km}$ até seu encontro com o rio Doce. Através do curso deste, foram carreados até a foz no Oceano Atlântico, chegando ao município de Linhares, no estado do Espírito Santo, em 21/11/2015, totalizando 663,2 km de corpos hídricos diretamente impactados (IBAMA, 2015).

Segundo o relatório da ANA (2016), o 'acidente de Mariana' ficou marcado na história do país como sendo o maior desastre ambiental já ocorrido. O acontecimento foi extremamente prejudicial, gerando impactos socioambientais que ainda hoje estão sendo dimensionados. Além de causar a morte de várias pessoas e deixar outras desabrigadas com a destruição do distrito de Bento Rodrigues, a ruptura da Barragem de Fundão, poluiu toda a extensão do Rio Doce, prejudicando os que dependiam dele para pesca e abastecimento, destruiu áreas de preservação permanente e vegetação nativa de Mata Atlântica, houve a mortandade da biodiversidade aquática e da fauna terrestre. Diante de tantos impactos gerados, a cidade de Governador Valadares foi bastante afetada, sendo prejudicada no seu abastecimento de água.

O relatório ainda afirma que a elevação na concentração de sedimentos e os níveis de turbidez em todo o rio Doce pela passagem da pluma de rejeitos acarretou na interrupção total ou parcial do abastecimento de água de 12 cidades que captam água diretamente no rio, além de impactar as captações de água outorgadas para fins industriais, de irrigação, criação de animais, e outros usos. Sendo que a passagem do pico da pluma de sedimentos durou aproximadamente 5 dias, porem o tempo durante o qual 
os níveis de turbidez ficaram acima de 1.000 Unidades Nefelométricas de Turbidez (UNT) em cada trecho do rio Doce foi superior a 30 dias.

\section{METODOLOGIA}

Para a execução do trabalho foram empregados os dados de Turbidez dos pontos de monitoramento existentes ao longo do Rio Doce, sendo os dados obtidos pelo monitoramento da água superficial do Instituto Mineiro de Gestão das Águas (IGAM), no percurso do rio contido no estado de Minas Gerais e pelo Instituto Estatual do Meio Ambiente do Espirito Santo (IEMA), no eixo do rio presente neste estado, os quais podem ser observados na figura 2.

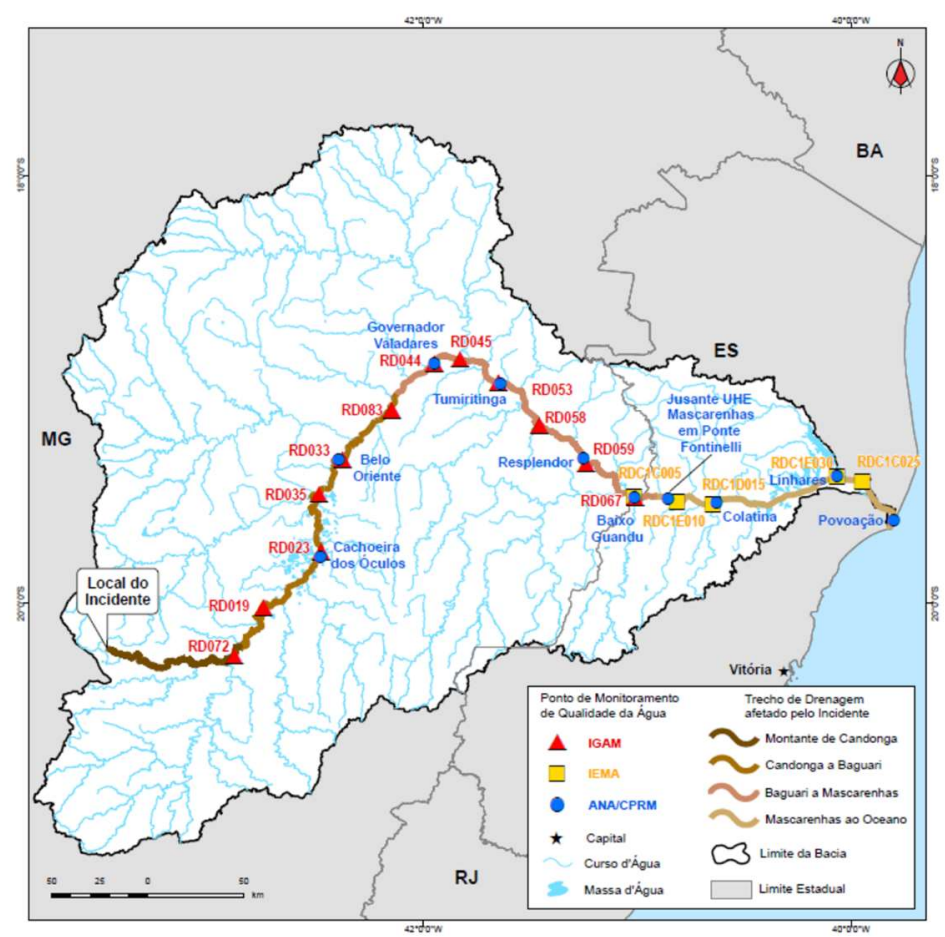

Figura 2: Pontos de monitoramento do Rio Doce. Fonte: ANA (2016).

Foram definidos os anos de 2015 a 2017 para a realização do estudo, recolhendo as informações disponíveis referentes às datas de monitoramento de interesse. Para a obtenção da reflectância nos pontos de monitoramento, foram selecionamos imagens disponibilizadas pelo INPE (Instituto Nacional de Pesquisas Espaciais) procurando encontrar imagens com as mesmas datas que foram realizadas as análises da água, para a realização de uma comparação adequada dos valores de turbidez e reflectância.

Assim, para a análise da resposta espectral da água, foram selecionadas cenas do satélite LandSat 8 , Sensor OLI, obtidas em datas em que haviam registros dos resultados de análise da água realizados pelo IGAM e pelo IEMA. Foi realizada a correção atmosférica das imagens selecionadas. Este processo consiste na transformação dos dados de números digitais, para reflectância planetária do topo da atmosfera e corrigindo o ângulo solar, de forma a permitir o cálculo da reflectância dos pontos escolhidos de modo adequado, corrigindo os efeitos atmosféricos. Os dados em números digitais escalonados da imagem foram convertidos 
para reflectância espectral utilizando-se a ferramenta de Álgebra de Mapas do software no qual a equação a seguir foi inserida:

$$
\left.\rho_{\lambda \prime}=M_{\rho} Q_{c a l}+A \rho \quad \text { (eq. } 01\right)
$$

Em que:

$\rho^{\prime}=$ reflectância no topo da atmosfera sem correção do ângulo;

$M=$ fator multiplicativo reescolado da Reflectância para a banda específica; $Q_{\text {cal }}=$ número digital do pixel; $A=$ fator aditivo reescolado da Reflectância para a banda específica.

De posse dos valores de refletância planetária do topo da atmosfera, foi empregada a equação 02 , para a correção do ângulo solar.

$$
\begin{array}{r}
\rho \lambda=\frac{\rho_{\lambda \prime}}{\sin \left(\theta_{S E}\right)} \quad \text { (eq. 02) } \\
\rho \lambda=\text { reflectância no topo da atmosfera com correção do ângulo solar; } \\
\rho_{\lambda^{\prime}}=\text { reflectância no topo da atmosfera sem correção do ângulo; } \\
\theta_{S E}=\text { Ângulo de elevação solar local. }
\end{array}
$$

O processo de correção atmosférica foram realizado nas bandas 3 e 4 de todas as imagens. Os pontos de monitoramento do IGAM e IEMA foram sobrepostos às imagens corrigidas e por meio de consulta espacial foram obtidos os valores de refletância em cada ponto monitorado. Os valores obtidos foram comparados com os valores de Turbidez em seus respectivos pontos a fim de se avaliar a possibilidade de se empregar dados de reflectância para o monitoramento do corpo hídrico.

\section{RESULTADOS E DISCUSSÃO}

Foram obtidas junto ao INPE trinta e nove cenas do satélite LandSat 8, sensor OLI, tendo como critério de busca a coincidência de datas de existência da cena e resultados de análise da qualidade da água realizadas pelo IGAM e IEMA. Por meio da tabela 01, observa-se em quais faixas espectrais as bandas do LandSat 8 atuam. Percebe-se que as bandas 3 e 4 atuam em faixas de comprimento de onda contidas a faixa de resposta espectral da água em estado líquido (figura 1), justificando a escolha destas para a realização deste.

Tabela 1: Comprimento de onda onde as bandas do LandSat 8 atuam.

\begin{tabular}{|l|l|}
\hline Bandas - LandSat 8 & Comprimento de onda $(\boldsymbol{\mu m})$ \\
\hline 1 & $0.43-0.45$ \\
\hline 2 & $0.45-0.51$ \\
\hline 3 & $0.53-0.59$ \\
\hline 4 & $0.64-0.67$ \\
\hline 5 & $0.85-0.88$ \\
\hline 6 & $1.57-1.65$ \\
\hline 7 & $2.11-2.29$ \\
\hline 8 & $0.50-0.68$ \\
\hline 9 & $1.36-1.38$ \\
\hline
\end{tabular}

Fonte: INPE (2018).

Foram selecionadas 17 (dezessete) cenas do satélite LandSat 8, sensor OLI. Para a realização do processo de correção atmosférica foram empregadas as bandas 3 e 4 e seus respectivos parâmetros de cena contidos na tabela 02, empregando-se a ferramenta 'Calculadora de raster' do SIG ArcGis, tendo como plano de informação as referidas bandas (3 e 4). 
$\mathrm{Na}$ imagem abaixo (figura 03) pode-se observar um recorte para o município de Governador Valadares/MG da cena após a aplicação do método de correção atmosférica, alterando os valores registrados nos pixels. Esta cidade está localizada na região central da bacia sendo uma das cidades impactadas pelo desastre que teve $100 \%$ do seu abastecimento interrompido em função da qualidade da água após a chegada da onda de rejeitos.

Tabela 2: Valores utilizados nas conversões.

\begin{tabular}{|l|l|l|l|l|}
\hline Data & Orbita/Ponto & Reflectância MULTI (M) & Reflectância ADD (A) & Ângulo de elevação solar local \\
\hline $12 / 11 / 2015$ & $217 / 074$ & 0,000020 & $-0,1$ & 65,367 \\
\hline $12 / 11 / 2015$ & $217 / 073$ & 0,000020 & $-0,1$ & 65,584 \\
\hline $21 / 11 / 2015$ & $216 / 073$ & 0,000020 & $-0,1$ & 65,354 \\
\hline $30 / 11 / 2015$ & $215 / 074$ & 0,000020 & $-0,1$ & 64,739 \\
\hline $07 / 12 / 2015$ & $216 / 073$ & 0,000020 & $-0,1$ & 64,006 \\
\hline $07 / 12 / 2015$ & $216 / 074$ & 0,000020 & $-0,1$ & 64,111 \\
\hline $14 / 12 / 2015$ & $217 / 073$ & 0,000020 & $-0,1$ & 65,578 \\
\hline $14 / 12 / 2015$ & $217 / 074$ & 0,000020 & $-0,1$ & 63,371 \\
\hline $16 / 12 / 2015$ & $215 / 074$ & 0,000020 & $-0,1$ & 63,149 \\
\hline $24 / 01 / 2016$ & $216 / 073$ & 0,000020 & $-0,1$ & 59,143 \\
\hline $31 / 01 / 2016$ & $217 / 074$ & 0,000020 & $-0,1$ & 58,453 \\
\hline $16 / 02 / 2016$ & $217 / 074$ & 0,000020 & $-0,1$ & 57,040 \\
\hline $28 / 03 / 2016$ & $216 / 073$ & 0,000020 & $-0,1$ & 52,419 \\
\hline $06 / 07 / 2016$ & $217 / 074$ & 0,000020 & $-0,1$ & 38,183 \\
\hline $17 / 01 / 2017$ & $217 / 073$ & 0,000020 & $-0,1$ & 59,658 \\
\hline $17 / 01 / 2017$ & $217 / 074$ & 0,000020 & $-0,1$ & 59,639 \\
\hline $26 / 01 / 2017$ & $216 / 073$ & 0,000020 & $-0,1$ & 58,946 \\
\hline
\end{tabular}

Fonte: Adaptado de INPE (2017).

Mapa de reflectância de Governador Valadares - 06 março de 2017
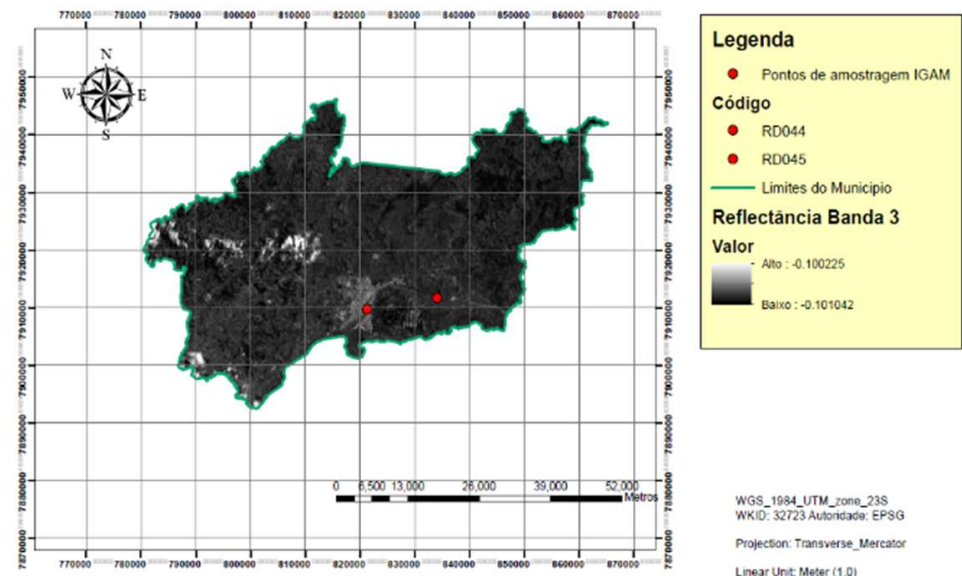

Figura 3: Cena convertida para Reflectância espectral.

Sobre as cenas convertidas para refletância foram adicionados os pontos de monitoramento do IGAM e IEMA e obtido, para cada ponto, o valor da refletância nas bandas 3 e 4 e os valores foram analisados tendo como parâmetro norteador da análise a Turbidez obtida no ponto para a data da imagem. Como a análise emprega o valor da turbidez obtida em campo, o número de cenas foi limitado, pois foram empregadas cenas e valores de turbidez em datas coincidentes, como apresentado na tabela 03.

Pode-se observar que dos trinta e um pontos avaliados, todos que apresentaram maiores teores de turbidez (destacados na tabela) apresentaram valores de refletância inferiores a 1 tanto na banda 3 como na 
banda 4. Houve dois pontos em que os valores de Reflectância foram inferiores a 1, contudo estes apresentavam baixos teores de turbidez, porém os valores de turbidez disponíveis para tais pontos eram do dia anterior à coleta das amostras, o que pode justificar o comportamento encontrado.

Tabela 3: Dados de turbidez e resposta espectral nos pontos de monitoramento do IGAM e IEMA em diferentes períodos de tempo.

\begin{tabular}{|c|c|c|c|c|}
\hline \multirow{2}{*}{ Ponto } & \multirow{2}{*}{ Data } & Reflectância & Turbidez (NTU) & \\
\hline & & B3 & B4 & \\
\hline \multirow{5}{*}{ RD072 } & $12 / 11 / 2015$ & 0,199104 & 0,237766 & 3410 \\
\hline & $14 / 12 / 2015$ & 0,245177 & 0,239722 & 870 \\
\hline & $31 / 01 / 2016$ & 0,096809 & 0,101952 & 1585 \\
\hline & $16 / 02 / 2016$ & 0,176462 & 0,160427 & 1320 \\
\hline & $17 / 01 / 2017$ & 1,668876 & 1,601529 & 267 \\
\hline \multirow{2}{*}{ RD019 } & $17 / 01 / 2017$ & 2,317818 & 2,28979 & 414 \\
\hline & $14 / 12 / 2015$ & 0,276228 & 0,324929 & 999 \\
\hline \multirow{4}{*}{ RD023 } & $12 / 11 / 2015$ & 0,21419 & 0,252081 & 6470 \\
\hline & $14 / 12 / 2015$ & 0,232125 & 0,335526 & 1078 \\
\hline & $16 / 02 / 2016$ & 0,186133 & 0,28446 & 5485 \\
\hline & $17 / 01 / 2017$ & 1,712087 & 2,362586 & 498 \\
\hline \multirow{4}{*}{ RD035 } & $12 / 11 / 2015$ & 0,210787 & 0,262571 & 168000 \\
\hline & $14 / 12 / 2015$ & 0,195658 & 0,3095 & 1602 \\
\hline & $16 / 02 / 2016$ & 0,167554 & 0,275509 & 12545 \\
\hline & $17 / 01 / 2017$ & 1,888045 & 2,531537 & 424 \\
\hline \multirow{3}{*}{ RD033 } & $12 / 11 / 2015$ & 0,216119 & 0,258887 & 23260 \\
\hline & $14 / 12 / 2015$ & 0,235281 & 0,334669 & 2261 \\
\hline & $17 / 01 / 2017$ & 3,01467 & 3,996205 & 463 \\
\hline \multirow{2}{*}{ RD083 } & $12 / 11 / 2015$ & 0,313022 & 0,401505 & 5910 \\
\hline & $17 / 01 / 2017$ & 3,926754 & 5,445459 & 225 \\
\hline \multirow{2}{*}{ RD044 } & $12 / 11 / 2015$ & 0,24738 & 0,365403 & 52420 \\
\hline & $14 / 12 / 2015$ & 0,255891 & 0,366304 & 907 \\
\hline \multirow{2}{*}{ RD045 } & $12 / 11 / 2015$ & 0,252853 & 0,35365 & 25420 \\
\hline & $14 / 12 / 2015$ & 0,248411 & 0,332292 & 748 \\
\hline \multirow{4}{*}{ RD053 } & $12 / 11 / 2015$ & 0,240047 & 0,319338 & 6470 \\
\hline & $14 / 12 / 2015$ & 0,216541 & 0,335993 & 1078 \\
\hline & $26 / 01 / 2017$ & 0,17494 & 0,199674 & $266^{*}$ \\
\hline & $17 / 01 / 2017$ & 3,918764 & 4,588076 & 498 \\
\hline \multirow{2}{*}{ RD058 } & $24 / 01 / 2016$ & 0,204519 & 0,261091 & 9168 \\
\hline & $26 / 01 / 2017$ & 0,158234 & 0,187396 & $58^{*}$ \\
\hline RD076 & $21 / 11 / 2015$ & 0,259311 & 0,454294 & 1548 \\
\hline
\end{tabular}

*Dados de turbidez do dia 25/01/2017.

Os corpos hídricos como um todo tem uma baixa porcentagem de reflectância, mas elementos presentes em seu curso podem afetar sua resposta espectral, por exemplo materiais inorgânicos presentes na água, que promovem o espalhamento da radiação, ou matéria orgânica que absorve a radiação. De acordo com o IBAMA (2015), o resíduo despejado no meio ambiente com o rompimento da barragem de Fundão, provenientes da extração do minério de ferros, é composto por materiais inorgânicos e classificado como não perigoso e não inerte para ferro e manganês. Por suas características, teoricamente, apresentaria uma alta porcentagem de reflectância quando disperso em água.

Ao compararmos a turbidez à reflectância dos pontos de monitoramento expostas na tabela 3 , podemos observar que após o rompimento da barragem os valores de reflectância na banda 3 e 4 diminuíram, com o aumento da turbidez. A queda da reflectância pode estar ligada a uma possível eutrofização do corpo hídrico, isso porque o aumento da turbidez dificulta a entrada de energia solar, 
inibindo o crescimento de espécies fotossintetizantes e fazendo com que haja uma diminuição na disponibilidade de oxigênio, o que favorece o crescimento de espécies aeróbicas. $O$ crescimento exagerado destas espécies interfere na resposta espectral, pois estes organismo absorvem a radiação.

Segundo Novo et al. (2001), a absorção de luz no meio aquático é governada pela presença de quatro componentes: a própria água, substâncias dissolvidas na água (em especial substância amarela ou matéria orgânica), biota fotossintetizadora (fitoplâncton e macrófitas quando presentes) e partículas não vivas (partículas orgânicas mortas e partículas inorgânicas). Os componentes descritos por estes autores encontravam-se presentes no rio nas datas das análises, parte devido ao rejeito advindo da barragem e também do arraste causado pela onda de cheia gerada, o que justifica a redução da refletância da água.

Rudorff et al. (2007), encontram em seus estudos faixas de absorção de radiação em torno de: 450 $\mathrm{nm}$, atribuindo tal absorção às propriedades espectrais conjuntas dos sedimentos em suspensão e da matéria orgânica dissolvida, quando avaliado em campo. A região avaliada pelos autores coincide, em parte, com a faixa de operação das bandas empregadas neste trabalho, assim também corrobora com os resultados encontrados.

\section{CONCLUSÕES}

Pela análise gerada, observou-se que os componentes presentes no Rio Doce propiciaram uma menor reflectância, nessa região do espectro (vermelho), comparado ao rio antes do rompimento da barragem. Não houve variação do resultado encontrado em função da localização espacial, pois o mesmo resultado foi detectado ao longo de todos os pontos de monitoramento no rio. Conclui-se, por fim, que quanto maior o valor da turbidez, menor será a Reflectância da água analisada após a adição de rejeitos, da mineração de ferro, em grandes volumes. Esta constatação reafirma a importância de trabalhos nesta área visto ser contrária ao esperado.

\section{REFERÊNCIAS}

ANA. Encarte Especial sobre a Bacia do Rio Doce Rompimento da barragem em Mariana/MG. Conjuntura dos recursos hídricos no brasil, Informe 2015. Brasília. 2016.

BIAS, E. S.; BARBOSA, F. L. R.; BRITES, R. S.. Emprego de imageamento passivo na análise da variabilidade espacial da turbidez no espelho d'água do Lago Paranoá, Distrito Federal. Eng Sanit Ambient., v.18, n.1, p.55-64, 2013.

COSTA, A.; FELIPPE, M. F.; REIS, G.. Licenciamento Ambiental de Grandes Empreendimentos Minerários: Dos Alarmes que Ninguém Escuta à Tragédia no Rio Doce. GEOgrafias, Belo Horizonte, ed. Especial, p.95-103, 2016.

IBAMA. Laudo Técnico Preliminar Impactos ambientais decorrentes do desastre envolvendo o rompimento da barragem de Fundão, em Mariana, Minas Gerais. Brasília, 2015.

IGAM. Monitoramento da qualidade das águas superficiais do rio Doce no Estado de Minas Gerais. Belo Horizonte, 2017.
INPE. Instituto Nacional de Pesquisas Espaciais. Satellites. 2018.

LANA, Z. M. O.. A atividade mineradora em Minas Gerais e em Ouro Preto: Impactos socioambientais e intervenções para a sustentabilidade. Sociedade e Território, Natal, v.27, n.3, p.45-59, 2015.

MOREIRA, M. A.. Fundamentos do Sensoriamento Remoto e Metodologias de Aplicação. 4 ed. Viçosa: UFV, 2012.

NOVO, E. M. L. M.. Sensoriamento remoto: princípios e aplicações. 3 ed. São Paulo: Edgard Blucher. 2008.

NOVO, E. M. L. M.; PONZONI, F. J.. Introdução ao Sensoriamento Remoto. Instituto Nacional de pesquisas Espaciais, Divisão de Sensoriamento Remoto, 2001.

VIOLA, Z. G. G.; ALMEIDA, K. C. B.; BARBOSA, F. A. R. Avaliação dos indicadores de qualidade de água para subsidiar propostas de conservação e manejo da bacia do 
Rio Doce em Minas Gerais - Brasil. In: CONGRESSO

INTERNACIONAL RESAG - GESTÃO DA ÁGUA E

MONITORAMENTO AMBIENTAL, 2. Anais. Aracaju, 2015.

FERREIRA, A. B.; PEREIRA FILHO, W.. Avaliação da reflectância espectral de corpos d'água em Santa Maria/RS por meio de espectrorradiometria de campo. Geoambiente On-line, n.13, p.194-207, 2009.
RUDORFF, C. M.; NOVO, E. M. L. M.; GALVÃO, L. S.; PEREIRA FILHO, W.. Análise derivativa de dados hiperespectrais medidos em nível de campo e orbital para caracterizar a composição de águas opticamente complexas na Amazônia. Acta Amazônica, v.37, n.2, p.269-280, 2007.

A CBPC - Companhia Brasileira de Produção Científica (CNPJ: 11.221.422/0001-03) detém os direitos materiais desta publicação. Os direitos referem-se à publicação do trabalho em qualquer parte do mundo, incluindo os direitos às renovações, expansões e disseminações da contribuição, bem como outros direitos subsidiários. Todos os trabalhos publicados eletronicamente poderão posteriormente ser publicados em coletâneas impressas sob coordenação da Sustenere Publishing, da Companhia Brasileira de Produção Científica e seus parceiros autorizados. Os (as) autores (as) preservam os direitos autorais, mas não têm permissão para a publicação da contribuição em outro meio, impresso ou digital, em português ou em tradução. 